\title{
Chapter 2 \\ Institutionalizing Ethical Debates \\ in Science, Technology and Innovation Policy: A Comparison of Europe, India and China
}

\author{
Frans W.A. Brom, Sachin Chaturvedi, Miltos Ladikas and Wenxia Zhang
}

\subsection{Introduction}

Recent decades have witnessed a significant increase in ethical debates on science, technology and innovation, in the sense of both greater intensity and a wider plurality of voices. In addition to the standard expert perspectives, more and more lay people have found a common voice to express their opinions. People fear the negative consequences of science, technology and innovation and want to protect fundamental social values against the intrusion of new values that appear to show less respect for living entities when these are instrumentalized through the scientific world-view. The European debate on genetic modification in agriculture is a well-documented example of the 'ethicization' of the public discourse on science, technology and innovation (Bovenkerk 2012).

F.W.A. Brom $(\bowtie)$

Rathenau Instituut and Ethics Institute, Utrecht University, P.O. Box 95366,

2509 CJ The Hague, The Netherlands

e-mail: F.Brom@Rathenau.nl; F.Brom@uu.nl

S. Chaturvedi

RIS, Zone IV-B, Fourth Floor, India Habitat Centre, Lodhi Road,

New Delhi 110003, India

e-mail: sachin@ ris.org.in

M. Ladikas

Centre for Professional Ethics, School of Health, University of Central Lancashire,

Brook 317, Preston PR1 2HE, UK

e-mail: MLadikas@uclan.ac.uk

W. Zhang

Chinese Academy of Science and Technology for Development (CASTED),

Beijing, People's Republic of China

e-mail: zhangwx@ casted.org.cn 
It is clear that ethics debates have become less 'expert' and more 'open' to participation by groups or individuals who do not necessarily claim any particular expertise, either in scientific subjects or in ethical theory, but are nevertheless persuaded that their voices are as valid as those of the experts. Ethical debates have developed in Europe in a form that allows input from experts and lay people alike, through various means such as opinion surveys and participatory policy discussions. These debates acquire public significance because they reach parliaments, governments and scientific organizations through institutionalized means that are aimed at influencing science, technology and innovation policy (Paula 2008).

Nowadays, developments in science, technology and innovation are global phenomena in which scientists and technology experts from different countries cooperate in international consortia. Innovative solutions are often transferred globally and adapted locally. Both in Europe and in the emerging economies of China and India, the core of science, technology and innovation policy is broadly similar: stimulating science and technology as important factors in developing innovative solutions to societal needs. Against this background, the Global Ethics in Science and Technology (GEST) project is interested in comparing Europe with China and India: to what extent is there a global ethics in science and technology, and how are ethical debates institutionalized in science, technology and innovation policies? The latter is the focus of this chapter.

The issue will be addressed as follows. First we will sketch the general policy on science, technology and innovation in all three regions and the position of ethics debates in it. The common idea in the respective policies is that science and technology are important factors in developing innovative solutions to societal needs, but these solutions might have a profound influence on the moral fabric of society. Questions have been raised with regard to justice, equity, autonomy, human dignity and social harmony (see Chaps. 5, 6 and 7). In these ethical debates, however, the tone of voice differs greatly from region to region. This leads to the question: is this attention to ethics solely lip service, or does it have a real impact on the regulatory frameworks of science, technology and innovation? We found that each region has a unique structure of ethics debates involving the institutionalization of three related tasks: ethical governance, ethical deliberation and ethical reflection. The remainder of this chapter describes these tasks and provides examples of the institutionalization of ethics debates.

With regard to ethical governance, in all three regions the governance of protecting explicitly accepted social values such as scientific integrity, or human subjects involved in research, is implemented in regulatory frameworks. With regard to animal research, there are clear differences from region to region. For governance this involves discussion of the content of common standards for science, technology and innovation in terms of academic integrity, the protection of human research subjects and the protection of animals, and of questions about how to ensure common standards and comparable practices.

As for ethical deliberation, the institutionalization of ethics debates in Europe functions as an amalgam of advisory systems that sound early warnings on new ethical issues relating to science, technology and innovation. In Europe, ethics 
debates are often a mix of expert-based and lay-based ethical deliberation. This leads to the institutionalization of engagement through participatory methodologies (see Chap. 4). In China and India, on the other hand, one cannot understand the institutionalization of ethical deliberation by looking at advisory committees that are directed at protecting social values and fundamental rights within developments in science, technology and innovation. The general tone of voice of ethics in science, technology and innovation debates in these countries is aimed at setting social agendas. A short description of India's science and technology policy clarifies this point. The value discussions are not institutionalized separately, but function as an integral part of the agenda-setting discussions (see Chap. 7).

Societies develop, which is why both tasks-ethical governance and ethical deliberation — need to be aligned with new societal and scientific developments. Ethics cannot function without systematic ethical reflection. This becomes clear when we see how ethics debates on new emerging technologies proliferate in emerging economies. Based upon China's experience with agricultural biotechnology, we see the need for broadening ethical deliberation and societal engagement as a part of an early warning system for ethical issues (see Chap. 9). This requires ethical reflection, not only in terms of academic research as a reflective practice that needs to be institutionalized, but also in terms of the development of societal reflection on core values, rights and ideals.

\subsection{Science and Technology for Innovation}

Science and technology are important factors in developing innovative solutions to societal needs. This idea is a strong driver behind the science, technology and innovation policies in all three regions. It is against this background that the role of ethics in the regulatory regimes has to be placed.

\subsubsection{Developing Innovative Solutions with Science and Technology}

The European Union formulated the idea of developing itself as a competitive knowledge society in the year 2000 as was a part of the so called Lisbon Strategy (2000-2010):

The Union has today set itself a new strategic goal for the next decade: to become the most competitive and dynamic knowledge-based economy in the world, capable of sustainable economic growth with more and better jobs and greater social cohesion (European Council 2000).

This strategy has been branded as the 'Innovation Union':

Innovation Union is the European Union strategy to create an innovation-friendly environment that makes it easier for great ideas to be turned into products and services that will bring our economy growth and jobs (European Commission 2014a). 
The Innovation Union is based in science and technology policy, where this policy is directed at 'turning our research into new and better services and products if we are to remain competitive in the global marketplace and improve the quality of life in Europe' (European Commission 2014b).

The challenge to Europe to remain globally competitive relates to the fundamental role of science, technology and innovation policy in competing regions such as India and China. In these regions science and technology policy have been an integral part of economic development. A rough outline of some of the dynamics in the regulatory regimes governing science, technology and innovation policy follows.

In India, the government's policy tools for setting out technology policy objectives and approaches are its science and technology policy statements. Since independence, four such statements have been issued, in 1958, 1983, 2003 and 2013. The 1958 statement was called 'Science Policy Resolution', that of 1983 'Technology Policy Statement', that of 2003 'Science and Technology Policy' and that of 2013 'Science, Technology and Innovation Policy'. These four documents have provided overarching frameworks for science and technology policy and have guided its societal linkages. The 2003 document also acknowledged the importance of linking modern technology with an indigenous knowledge base, and technology was part of a framework for an independent industrial base to be achieved through planned economic growth (Baark 1986). This led to the creation of a huge institutional base of organizations funding research and development and of research institutes.

The latest government policy statement, Science, Technology and Innovation Policy 2013 (DST 2013), mentions 'a strong and visible Science, Research and Innovation System for High-Technology-led path for India (SRISHTI) as the goal of the new STI Policy' and 'science, technology and innovation for the people' as the new paradigm of the Indian science, technology, innovation enterprise. It argues that the national science, technology and innovation system must therefore recognize Indian society as its major stakeholder: 'Innovation for inclusive growth implies ensuring access, availability and affordability of solutions to as large a population as possible.' It states that the policy will drive both investment in science and the investment of science-led technology and innovation in select areas of socioeconomic importance. It acknowledges that public understanding of science is an important dimension of reaching the people and introducing the benefits of modern science and technology to them. According to the new policy, the guiding vision of aspiring Indian science, technology and innovation enterprise is to accelerate the pace of the discovery and delivery of science-led solutions for faster, sustainable and inclusive growth.

China has, since the adoption of the reform and opening-up policy in 1978, been following the lead set by Deng Xiaoping's observation that 'science and technology are the primary productive forces', and pursuing a science and technology development strategy which stresses that 'economic development must be based on science and technology, and science and technology must serve the need of economic development' (Deng 1993). In 2007, the Chinese government set a new strategic 
objective of 'enhancing indigenous innovation capacity and building an innovationoriented country'. The history of China in the past century shows that recognition of the important role of science and technology has played a crucial part in every major decision affecting economic and social development strategy in China. It also clearly demonstrates that the Chinese people cherish the value of science and technology and that China is firmly committed to catching up with the world's leading nations in science and technology. Through one hundred years of hard effort, China has made notable progress in science and technology development, having started with a blank slate. In the meantime, a big proportion of the Chinese public now recognizes the importance of science and technology and the dominant position of science and scientific pragmatism in the mainstream value system.

\subsection{2 'Ethics Debates': Discussing the Societal Impact of Science, Technology and Innovation Policies}

It is clear that, as one might expect, science, technology and innovation policies have not, in any of the three regions, been blind to the impact of scientific and technological developments on the moral fabric of society. Questions have been raised about the impact of science, technology and innovation on dominant social values such as justice, equity, autonomy, human dignity and social harmony, relating to both individual and social life.

A recent example of the European tone of voice in raising ethical questions in the science, technology and innovation debate was a resolution on science and technology ethics adopted with an overwhelming majority by the senate of the Netherlands (Eerste Kamer 2014). The senate concluded that technological innovations were necessary for a competitive economy, that some technological innovations, such as the convergence between nanotechnology, information technology, biotechnology and cognitive science, might have profound consequences for privacy and citizenship, and that these consequences raised fundamental ethical questions. Based upon this conclusion, the senate asked the government to structurally embed ethics in its technology and innovation policy and to inform the senate regularly of the results. This tone of voice in raising ethical questions in the debate on science, technology and innovation signifies a recognition of the importance of technological innovation for a competitive economy, while at the same time stressing that its consequences for social values and fundamental rights need close scrutiny.

Value questions are not, of course, exclusive to Europe: they have also been raised in India and in China.

An example of the Chinese tone of voice is what then Chinese president Jiang Zemin pointed out at a meeting with Nobel laureates in Beidaihe on 5 August 2000:

The issue of scientific ethics is going to become more prominent in the 21 st century. The bottom line is: advances in science and technology should serve the interests of the mankind, serve the lofty cause of world peace, development and progress, rather than hurt the 
human race itself ... To build and improve scientific ethics, respect and protect intellectual property rights, and provide policy guidance for the research and use of science and technology in ways that meet the common interests of people around the world is a major issue to be resolved in the 21st century (Jiang 2000).

That science, technology and innovation should be directed at the interests of humankind and the benefits broadly accessible in society has been a core issue in the ethics debates in India, where 'access' itself is a larger issue that provokes intense and passionate debate when intellectual property rights are under discussion. India's tone of voice can be discerned from the debate's focus on inclusion and equity. These are brought up against the background of wider inequality within the country and across various regions. The idea of ethics in this respect is also significant, since technology and gender divides are strongly evident across the board. Access, equity and inclusion have repeatedly been emphasized in the series of fiveyear plans emanating from India's Planning Commission (Planning Commission 2011). The focus on inclusion and access has primarily been in policy statements, however; there are not many reports or studies on evaluated actual implementation.

\subsubsection{An Amalgam of Institutionalizations}

To the question posed above-is this attention to ethics solely lip service, or does it have a real impact on the regulatory frameworks of science, technology and innovation policies? - we can attest that there is a broad and interesting discussion on the institutionalization of ethics debates in science, technology and innovation policy in all three regions. Our research identified a variety of structures, ranging from institutes and committees that are part of government departments to armslength quasi-governmental organizations and influential non-governmental entities that include ethics in their remits.

Presenting a complete overview would be neither helpful nor possible. Institutional structures are dynamic fields that change and develop along with science, technology and innovation policies. Detailed descriptions could only have temporary value. As political and regulatory perspectives change, committees are established, transformed, merged and eventually abandoned, while regulation adapts to new situations and issues. Instead of striving for a full description of the amalgam of institutions in the three regions, we propose a systematic description of the three main tasks that the institutionalizations of ethics debates in science, technology and innovation policy concentrate on. This is based on a synthesis of the empirical material analysed as part of the GEST project. We will undertake this along three lines of inquiry:

- ethical governance: institutionalizing ethics debates in terms of the implementation of standards in research ethics in science, technology and innovation policies

- ethical deliberation: institutionalizing ethics debates that raise ethical issues in scientific and technological developments in science, technology and innovation policies 
- ethical reflection: institutionalizing ethics debates that support critical reflection and engagement in debates on research standards, emerging technology issues and social justice in science, technology and innovation policies.

\subsection{Ethical Governance}

The first function that one sees in the institutionalization of ethics debates is the institutionalization of compliance. Ethics debates do not start from scratch: some of the values, rights and ideals that are relevant to the development of science, technology and innovation are already broadly shared and sometimes even explicitly codified in codes of conduct or legal requirements for research. These form the firm core of research ethics describing behaviour with regard to science (scientific integrity) and with regard to society (human research subjects, animals and the environment). There are three fields of governance in which ethics is of clear importance for the societal impact of science and technology directed at innovation:

- academic integrity

- research (including medical research) involving human subjects

- research involving animals.

\subsubsection{Academic Integrity}

There is a debate on academic integrity evolving in all three regions. Our analysis shows that this debate is very intense in Europe and has recently become so in China. The discussion on research integrity and compliance with standards of academic integrity forms an important focus point for the discussion on the ethics of science, technology and innovation in China. The core question here concerns the relationship between academic integrity and broader issues of science, technology and innovation ethics. Here are three examples from the respective regions:

- The UK Research Integrity Office, an independent body that provides expert advice and guidance on the conduct of research, covers all subject areas and helps everyone involved in research deal with integrity issues.

- In China the Ministry of Science and Technology has established an office for research and development integrity and a committee that focuses on developing research and development integrity to administer issues concerning the research and development ethics of Chinese scientists.

- The Department of Biotechnology in India's Ministry of Science and Technology has issued a 'Statement on Handling of Allegations of Research Misconduct' for departmentally funded organizations and researchers all across the country. The department asserts that integrity is naturally expected in the 
communication of science through seminars, meetings and publications. The policy statement also stipulates punishments for research misconduct.

\subsubsection{Research on Human Subjects}

In all three regions there is a strong focus on the institutionalization of research ethics involving human research subjects, especially in medical research (Jesani 2009; Muthuswamy 2010). The main question in this field is whether the regulations and institutionalizations are comparable between the different regions.

\subsubsection{Protecting Research Animals}

With regard to the ethics debate on animals in research, we find comparable structures in Europe and India in terms of national legislation and ethics committees at institutional level. In China, discussion on the use of animals in research is not prominent. The core question for a global ethics of science, technology and innovation revolves around two issues: the fundamental ethical question of whether, why and how animals are to be considered proper objects of moral concern, and the practical ethical question of comparing existing regulations and applications in the field of animal research.

\subsubsection{Conclusion}

Overall, the institutionalization of ethics debates in the field of governance highlights the importance of further comparing ethical standards and their application in practice. In other words, the challenges confronting the development of a global ethics in science, technology and innovation in relation to governance are:

- To what extent are common standards for science, technology and innovation with regard to academic integrity, the protection of human research subjects and the protection of animals necessary and possible?

- How does one ensure that common standards lead to the development of comparable practices?

\subsection{Ethical Deliberation: Explicating Ethical Issues in Science, Technology and Innovation Developments}

New emerging technologies raise new ethical issues. From a European perspective, the institutionalization of ethics debates functions as an advisory system that issues early warnings about new ethical issues relating to science, technology and 
innovation. The existing and developing European institutes are directed at opening up new developments for ethical deliberation. Official advisory reports place these issues on the policy agenda with authority and inform policymakers and researchers of relevant issues to consider. Developing ethical deliberation is often a mix of expert-based and society-based ethical deliberation. Engagement through participatory trajectories is a crucial part of the institutionalization of ethical deliberation (see Chap. 4).

In order to understand the institutionalization of ethical deliberation in India and China, however, we should look beyond advisory committees that are directed at protecting social values and fundamental rights against developments in science, technology and innovation. In Sect. 2.2.2 we saw that the general tone of voice of ethics within science, technology and innovation debates is directed at priority setting in order to solve broad societal issues and improve the life situation of those in need-in other words, setting social justice innovation agendas. Instead of an examination of individual committees, a description of the history of the agenda-setting process might help clarify the ethics structure in these regions. An example from India will clarify this point.

\subsubsection{Ethics Advisory Committees}

One way in which ethical debates are institutionalized to foster engagement in public discourses on regulations, politics and governance is by the installation of official ethics advisory committees that give public advice aimed at broadening policy discourses. These committees institutionalize ethics debates if, and only if, they advise publicly. Giving advice based upon accessible systematic reflective argumentation broadens the possibilities of public engagement in the discussion. Once arguments are given publicly, they can be challenged publicly too.

The idea of the ethics advisory structures in Europe follows strongly the tone of voice as described above in Sect. 2.2.2: recognizing the importance of technological innovations for a competitive economy while at the same time stressing that their consequences for social values and fundamental rights need close scrutiny. The ethics structures need to advise how the social values and fundamental rights can be protected.

\subsubsection{Ethics in Agenda Setting in Science, Technology and Innovation}

The institutionalization of the ethics debates in India and China does not follow the pattern of advisory committees directed at protecting social values and fundamental rights against developments in science, technology and innovation. An outline of the history of Indian research and development policy makes it clear that institutionalizations aim to steer developments in science, technology and 
innovation towards solving broad societal issues and improving the life situation of those in need: in other words, setting social justice innovation agendas.

India embarked upon an ambitious development path after gaining independence in 1947. Led by the visionary prime minister Jawaharlal Nehru, the government revamped the science and technology infrastructure and established many new laboratories across the country. Their vision was to harness science and technology for social development and economic growth. The various national plans and science and technology policies recognize that science and technology are vital aspects of national capability. The central focus of the Twelfth Five Year Plan for the period 2012-2017 is to ensure that science and technology become major drivers in the process of national development (GOI 2012). The government has declared 2010-2020 the Decade of Innovation, with the object of achieving access, equity and inclusion. In fact, this has been on the agenda of the government since the 1950s.

The Scientific Policy Resolution of 1958, the Technology Policy Statement of 1983, the Science and Technology Policy of 2003 and the Science, Technology and Innovation Policy of 2013 categorically declare that science and technology have an unprecedented impact on economic growth and social development. They state that one of the aims of the policy is to secure for the people of the country all the benefits that can accrue from the acquisition and application of scientific knowledge. The objective is to ensure the security of the people in terms of food, agriculture, nutrition, the environment, water, health and energy on a sustainable basis, with special emphasis on equity in development, so that the benefits of technological growth reach the majority of the population, particularly the disadvantaged, leading to an improved quality of life for every citizen. According to the new Science, Technology and Innovation Policy, the guiding vision of aspiring Indian science, technology and innovation enterprise is to accelerate the pace of the discovery and delivery of science-led solutions for faster, sustainable and inclusive growth.

The policies also call for close coordination of the various government departments, and also among those concerned, at all levels, with any sector of economic, scientific or technological activity, and not least the understanding and involvement of the entire Indian people. It is realized too that 'scientific and technological developments today also have deep ethical, legal and social implications. There are deep concerns in society about these. ... Scientific work and policies arising from these have to be highly transparent and widely understood' (DST 2003).

The Science, Technology and Innovation Policy of 2013, which is the latest such document, states that 'a strong and visible Science, Research and Innovation System for High-Technology-led path for India (SRISHTI) is the goal of the new STI Policy' and 'science, technology and innovation for the people' is the new paradigm of the Indian science, technology and innovation enterprise. It declares that the national science, technology and innovation system must therefore recognize Indian society as its major stakeholder: 'Innovation for inclusive growth implies ensuring access, availability and affordability of solutions to as large a population as possible.' It says that the policy will drive both investment in science and the 
investment of science-led technology and innovation in select areas of socioeconomic importance. It acknowledges that the public understanding of science is an important dimension for reaching the people and introducing the benefits of modern science and technology to them. However, it also argues that this public and political understanding of science should be based on evidence and debated with an open mind. 'People and decision makers must be made aware of the implications of emerging technologies, including their ethical, social and economic dimensions' (DST 2013). This new policy acknowledges the increasing role of the private sector in research and development and advocates the public-private partnership model.

Within these policy contours, the Department of Science and Technology, as part of its 'S\&T Programmes for Socio-Economic Development' has set up a Science for Equity, Empowerment and Development Division. This has the objective of 'working for technological empowerment and sustainable livelihoods at the grass-root levels', aiming at the socioeconomic upliftment of poor, disadvantaged sections of society. The department has programmes to facilitate participation by women in science and technology. It has also established a Nanotechnology Mission to give emphasis to research and development and capacity building in nanosciences and technology, with a view to harnessing these to address societal challenges and economic growth by leveraging its industrial applications. Similarly, the Department of Biotechnology has initiated many programmes in frontier areas of the biosciences.

Thus the orientation of science and technology programmes has been to use science and technology for development purposes, and to catch up with advanced countries. From time to time the Indian Council of Medical Research issues ethical guidelines for biomedical research on human participants (ICMR 2006). These stipulate that all research involving human participants should be conducted in accordance with the four basic ethical principles, namely autonomy (respect for persons or participants), beneficence, non-maleficence (do no harm) and justice (Kumar 2006). The council's Health Research Policy (ICMR 2007), in its section on operating principles, says that the ethical guidelines should be mandatory for all research.

\subsubsection{Conclusion}

Europe, India and China can learn from one another. The discussion in Europe could benefit from the Indian example of opening up the agenda setting for science, technology and innovation to broader value-based discussions. The basic idea of responsible research and innovation in the EU's new Horizon 2020 agenda might give opportunities for this, while the existing amalgam of European ethics advisory structures as an early warning system might also be a source of inspiration for China and India. This is because, as the next section of this chapter will demonstrate, strong societal debates on emerging technologies are popping up in 
China and India too. A telling example of such a debate is the discussion on agricultural biotechnology in both China and India.

\subsection{Ethical Reflection}

Ethical discussion on new emerging technologies has proliferated in China and India. The example of agricultural biotechnology shows the need to broaden the ethics debate and for societal engagement through participatory trajectories as an early warning system. The Chinese example serves to clarify this point.

A genetically modified cotton variety developed by Monsanto was introduced to China in 1995, for the purpose of dealing with severe outbreaks of bollworm. Meanwhile, the Chinese government was also intensifying its efforts to develop related biological technologies. In China, the discourse on supporting genetically modified foods and related technologies through innovation takes the form of two intertwined systems. The first is the discourse of developmentalism and the second the discourse of scientism, both of which provide an excellent environment and great opportunities for the development of genetic modification. Whether in scientific research or industry development, the government of China has given substantial support to modern biotechnology as a national strategy. Hence genetically modified crops are developing rapidly in the country and enjoy strong market opportunities. In addition to the cotton variety, genetically modified crops and products that have been granted biosafety certificates since 1998 include tomato, papaya, pimento and animal vaccines.

In August 2009, China's Ministry of Agriculture formally approved the issuing of safety certificates to two transgenic rice varieties and a transgenic corn variety. When Greenpeace International learned of this and made it widely known through the media, a huge public backlash ensued. In a demonstration of widespread concern about genetically modified crops, there was much discussion in both traditional and online media. Some unverified negative reports were widely circulated. In March 2010, the Center for Science Communication, Peking University, published on its official website an open letter jointly signed by some scholars in humanities and social sciences, claiming that the safety certificates granted to the transgenic rice and maize varieties 'were not based on adequate demonstration. If decisive measures are not taken immediately to put a halt to commercial planting of genetically modified corps, China's food security and food sovereignty will face major impacts.' The views carried by the media have a strong influence on the degree of acceptance among Chinese consumers for genetically modified foods. Because the debate on these foods has not been settled, the majority of people with no interest in the scientific details of the issue have left the middle ground to join the conservative camp. In recent years, as urban consumers have become more aware of genetically modified foods, acceptance of these foods has decreased. 


\subsection{Conclusion}

We conclude that the institutionalization of ethics debates in science, technology and innovation needs to be analysed from three different perspectives, each of which has a unique structure: ethical governance, ethical deliberation and ethical reflection.

From the ethical governance perspective, deliberation targets compliance issues within the existing ethical frameworks. The institutionalization of ethics debates in the field of governance highlights two challenges for the development of a global ethics in science, technology and innovation in relation to governance:

- the extent to which common standards for science, technology and innovation with regard to academic integrity, the protection of human research subjects and the protection of animals are necessary and possible

- how to ensure that common standards lead to the development of comparable practices.

In ethical deliberation, new emerging issues and the social agenda for science, technology and innovation are debated. The idea of the ethics advisory structures in Europe follows strongly a tone of voice that recognizes the importance of technological innovations for a competitive economy, while at the same time stressing that its consequences for social values and fundamental rights need close scrutiny. European ethics structures are designed to provide advice on how to protect social values and fundamental rights. The Chinese and Indian advisory structures on science, technology and innovation, in which new emerging issues and the social agenda are debated, aim to steer developments in science, technology and innovation towards solving broad societal issues and improving the life situation of those in need: in other words, setting social justice innovation agendas.

Finally the institutionalization of societal and academic reflection on ethics to feed governance and deliberation shows that the ethical debate on new emerging technologies has flourished in China and India. Agricultural biotechnology shows the need to broaden the ethics debate and for societal engagement through participatory trajectories as an early warning system. Societal and academic reflection is directed at the question: how does one organize these trajectories? (see also Chap. ...).

\subsection{Background Material}

This chapter builds upon the reports of the EU research project Global Ethics in Science and Technology (GEST), specifically the following:

EU country reports from Deliverable 1.1, Ethics state of the art: EU debate

- Chapter 2: S\&T ethics advisory structures in the United Kingdom, by Miltos Ladikas and Cathy Lennon (University of Central Lancashire) 
- Chapter 3: S\&T ethics advisory structure in Germany, by Leonhard Hennen (Institute for Technology Assessment and Systems Analysis-ITAS) and Arnold Sauter (ITAS and Office of Technology Assessment at the German Bundestag)

- Chapter 4: S\&T ethics structure in Netherlands, by Virgil Rerimassie, Frans W.A. Brom (Rathenau Instituut)

GEST background papers

- Ethics state of the art: Yesterday, today, and tomorrow in China, by Wenxia Zhang, Yandong Zhao Ying Ma, Miao Liao (Chinese Academy of Science and Technology for Development)

- Science and technology policy in India: Policy contours, institutional framework and ethical considerations, by Sachin Chaturvedi, K. Ravi Sriniva, Pallavi Singh (Research and Information System for Developing Countries, New Delhi)

In these reports the data collected is available for further analysis and discussion. These reports are available on the GEST project website and in the deliverables (EU website) for the European Commission.

Open Access This chapter is distributed under the terms of the Creative Commons Attribution Noncommercial License, which permits any noncommercial use, distribution, and reproduction in any medium, provided the original author(s) and source are credited.

\section{References}

Baark E (1986) Information infrastructure in India and China. In: Baark E, Amison Jamison (eds) Technological development in China, India and Japan. Cross cultural perspectives. Macmillan, London

Bovenkerk B (2012) The biotechnology debate: democracy in the face of intractable disagreement. Springer, Dordrecht

Deng X (1993) Deng Xiaoping anthology, vol 3. People's Press, Beijing

DST (2004) Annual Report 2003-04. Department of Science and Technology, Ministry of Science and Technology, Government of India, New Delhi

DST (1985) Annual Report 1984-45. Department of Science and Technology, Ministry of Science and Technology, Government of India, New Delhi

DST (2003) Science and Technology Policy. Department of Science and Technology, Government of India, New Delhi

DST (2013) Science, Technology and Innovation Policy. Department of Science and Technology, Government of India, New Delhi

Eerste Kamer (2014) Motie-Ester (ChristenUnie) c.s. inzake reflectie op ethische vragen in het technologie- en innovatiebeleid. EK 33.750 XIII, E

European Council (2000) Presidency conclusions. Lisbon European Council, 23, 24 March 2000. http://www.consilium.europa.eu/uedocs/cms_data/docs/pressdata/en/ec/00100-r1.en0.htm. Accessed 22 July 2014

European Commission (2014a) Innovation Union: a Europe 2010 initiative. http://ec.europa.eu/ research/innovation-union/index_en.cfm. Accessed 11 July 2014

European Commission (2014b) Why do we need an innovation union? http://ec.europa.eu/ research/innovation-union/index_en.cfm?pg=why. Accessed 11 July 2014 
GOI (2012) 12th Five-Year Plan 2012-2017. Planning Commission, Government of India. SAGE Publications India Pvt Ltd, New Delhi

ICMR (2006) Ethical guidelines for biomedical research on human participants. Indian Council of Medical Research, New Delhi

ICMR (2007) Health research policy. Indian Council of Medical Research, New Delhi

Jesani A (2009) Ethics in ethics committees: time to share experiences, discuss challenges and do a better job. Indian J Med Ethics 6(2):62-63

Jiang Z (2000) Remarks in a meeting with Nobel Laureates in Beidaihe, 5 August 2000

Kumar N (2006) Bioethics activities in India. Eastern Mediterr Health J 12(1):56-65

Muthuswamy V (2010) The central ethics committee on human research in India. In: UNESCO (ed) National Bioethics Committees in Action. UNESCO, Paris

Paula LE (2008) Ethics committees, public debate and regulation: an evaluation of policy instruments in bioethics governance. PhD thesis. Free University, Amsterdam

Planning Commission (2011) Faster, sustainable and more inclusive growth. An approach to the 12th Five Year Plan. Planning Commission, New Delhi

Ram A (1968) Science in India: some aspects. Address at the Indian Science Congress, January. Science and Culture 34(1) 